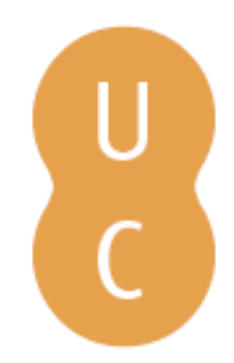

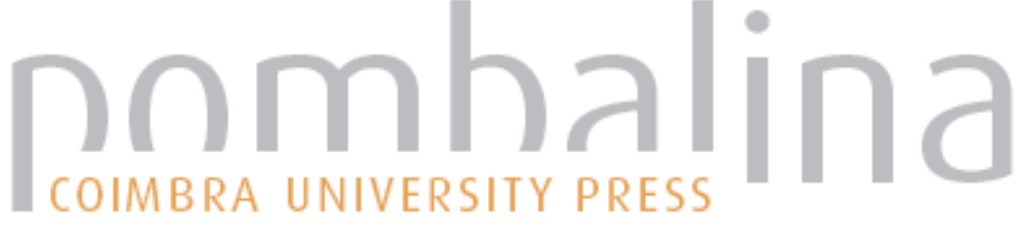

\section{A nominalização do infinitivo em duas sincronias do português}

\author{
Autor(es): Oliveira, Inês
}

Publicado por: Imprensa da Universidade de Coimbra

URL

persistente: URI:http://hdl.handle.net/10316.2/32248

DOI: $\quad$ DOI:http://dx.doi.org/10.14195/978-989-26-0714-6_4

Accessed : $\quad$ 26-Apr-2023 11:06:36

A navegação consulta e descarregamento dos títulos inseridos nas Bibliotecas Digitais UC Digitalis, UC Pombalina e UC Impactum, pressupõem a aceitação plena e sem reservas dos Termos e Condições de Uso destas Bibliotecas Digitais, disponíveis em https://digitalis.uc.pt/pt-pt/termos.

Conforme exposto nos referidos Termos e Condições de Uso, o descarregamento de títulos de acesso restrito requer uma licença válida de autorização devendo o utilizador aceder ao(s) documento(s) a partir de um endereço de IP da instituição detentora da supramencionada licença.

Ao utilizador é apenas permitido o descarregamento para uso pessoal, pelo que o emprego do(s) título(s) descarregado(s) para outro fim, designadamente comercial, carece de autorização do respetivo autor ou editor da obra.

Na medida em que todas as obras da UC Digitalis se encontram protegidas pelo Código do Direito de Autor e Direitos Conexos e demais legislação aplicável, toda a cópia, parcial ou total, deste documento, nos casos em que é legalmente admitida, deverá conter ou fazer-se acompanhar por este aviso.

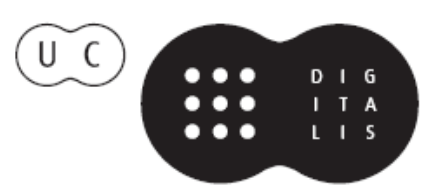




\section{ESTUDOS DE \\ LINGUÍSTICA}

VOLUME II

CONCEIÇÃO CARAPINHA

ISABEL A. SANTOS

COORD.

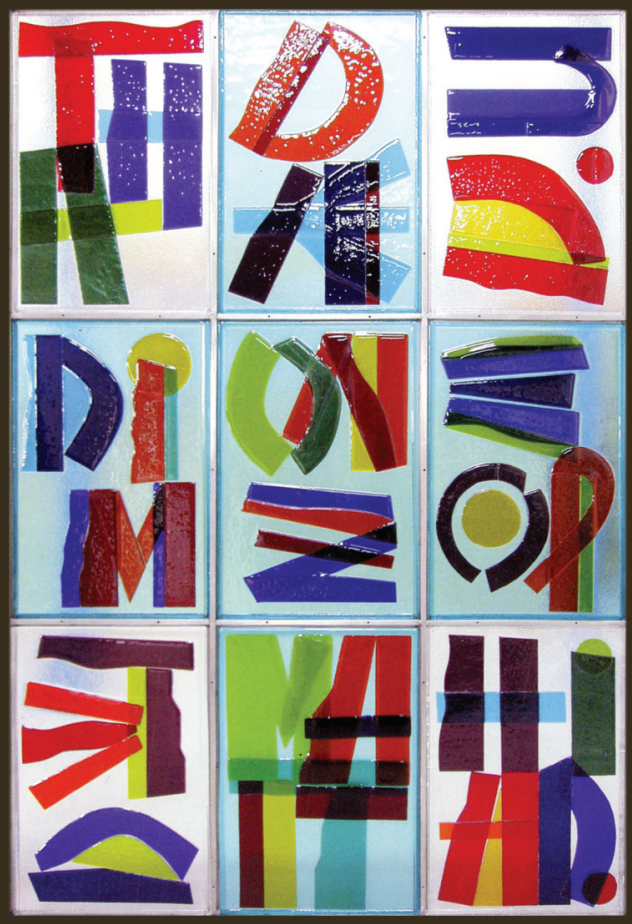




\section{A NOMINALIZAÇÃo DO INFINITIVO EM DUAS SINCRONIAS DO PORTUGUÊS 38}

Inês Oliveira Centro de Linguística da Universidade do Porto Escola Superior de Educação do Instituto Politécnico do Porto inesoliveira@ese.ipp.pt

\section{Introdução}

A língua ... é um fazer-se num quadro de permanência e continuidade. ${ }^{39}$

O infinitivo é uma estrutura híbrida e nem sempre os gramáticos da tradição luso-brasileira esclareceram a sua pertença a uma categoria verbal ou nominal. Na verdade, este é usado enquanto forma verbal, sobretudo em estruturas de subordinação, mas também é usado enquanto forma nominal.

A nominalização do infinitivo é um processo existente em diferentes línguas românicas, como o espanhol, o italiano, o francês (em escala reduzida) e o português. No português, este uso nominal do infinitivo é já referenciado por alguns autores como existente no período arcaico.

38 Este estudo insere-se no âmbito do primeiro ano de doutoramento em Linguística e foi realizado para o seminário de Linguística Histórica.

39 Coseriu, 1979: 237 
Mattoso Câmara Jr. (1975) refere a criação de substantivos, no período arcaico, pela nominalização do infinitivo ${ }^{40}$.

Mattos e Silva (2008: 25), na caracterização do português arcaico, considera a seguinte hipótese: "sendo o presente do português continuador do seu passado, será ele referência indispensável para olhar o passado". Esta hipótese resulta dos trabalhos de William Labov (1975:829), que debruçando-se em mudanças do tempo aparente, era possibilitado o estudo do que teria ocorrido no tempo real, nomeadamente, ver o passado a partir de variações do presente. Se acreditarmos nesta hipótese da autora, é provável que encontremos algumas ocorrências do infinitivo nominalizado também em textos do passado.

Neste estudo, procuramos analisar a ocorrência de um uso nominal do infinitivo em duas sincronias da língua portuguesa, englobando o período medieval e o clássico de forma a responder a dois objetivos:

(i) por um lado, pretendemos comprovar em sincronias do passado a existência ou não de nominalização do infinitivo;

(ii) por outro lado, pretendemos justificar a lexicalização de alguns infinitivos pela sua frequência em textos do passado.

Considerando estes objetivos, definir-se-ão corpora representativos destes dois períodos.

Este trabalho encontra-se estruturado em quatro partes. Na primeira - Introdução- definem-se os objectivos e apresenta-se a organização do estudo. A segunda - O Infinitivo - integra dois pontos que têm como objectivo situar a questão do infinitivo nos gramáticos da tradição luso-brasileira. No primeiro capítulo, analisamos o infinitivo latino, a sua construção e usos, para posteriormente, no segundo capítulo, verificarmos as semelhanças e diferenças em relação ao infinitivo português.

40 Mattoso Câmara Jr. (1975: 215) refere-se ao "emprego como substantivo, com a possibilidade de plural nominal em -es e a determinação pelo artigo do infinitivo verbal: o falar, os falares de uma língua, etc". Mattos e Silva (2008: 344) dá exemplos deste processo em textos do século XIII e do século XIV e designa este processo de heterocategorial em que a base é um verbo e o seu produto um nome. 
Procuraremos a partir do infinitivo latino encontrar uma justificação para a ocorrência de um uso nominal do infinitivo no português actual. $\mathrm{Na}$ terceira parte - O corpus -, subdividida em dois pontos, delimitamos o corpus para análise que seja ilustrativo dos dois períodos em estudo: medieval e clássico. Assim, seleccionamos a Primeyra Partida, um texto jurídico da legislação de Afonso X, para o período medieval, e para o período clássico baseamo-nos no Índice de Formas de Paiva (2002). Apresentamos os critérios adoptados na pesquisa do corpus da Primeyra Partida e apontamos algumas informações importantes no que diz respeito à catalogação das formas verbais no corpus de Paiva (2002). De seguida, procede-se à análise das ocorrências encontradas e à discussão dos dados em que se procura delinear qual o período de maior incidência do fenómeno em análise. Nessa discussão, abrimos um ponto em que referimos o caso do infinitivo lexicalizado, contextualizando diacronicamente o fenómeno da lexicalização. Na quarta parte - Conclusão - resumem-se as conclusões gerais deste estudo, articulando as informações iniciais sobre o infinitivo latino com a análise do corpus.

\section{2. $O$ infinitivo}

\subsection{A problemática da caracterização do infinitivo}

Na tradição dos gramáticos luso-brasileiros, a caracterização do infinitivo nem sempre é clara e precisa. As várias designações atribuídas ao infinitivo colocam em relevo uma natureza dupla: verbal e nominal. Ali (1964:129) caracteriza o infinitivo como "forma com aparência e função de substantivo". Cuesta e da Luz (1980:404) designam-no como 'substantivo verbal'. Cunha e Cintra (2002: 378) apelidam-no de 'forma nominal do verbo'. Nestas definições observa-se um vaivém entre a categoria do nome e a do verbo, não sendo definidas fronteiras claras entre as duas. Os vários gramáticos mencionados referem que o infinitivo tanto possui uma função verbal - e, desta forma, pode aparecer com advérbios, com pronomes átonos, com complementos directo e indirecto e mesmo vir 
acompanhado de sujeito -, como possui uma função nominal, sendo possível ser regido por preposições.

Se analisarmos os nomes e dos verbos, verificamos que têm propriedades distintas do ponto de vista morfológico, sintáctico e semântico. Nas línguas flexionais, os verbos têm morfema de tempo, de modo, de aspecto, de pessoa e de número e, sintacticamente, a sua função primordial é a de predicado da oração. Semanticamente, os verbos denotam acções ou estados. Nestas mesmas línguas, os nomes contáveis têm flexão em número e sintacticamente podem ser acompanhados de determinantes, de quantificadores, de complementos e de modificadores. Semanticamente, um nome comum tem a função de nomeação de seres/entidades concretas ou abstractas.

No entanto, existem afinidades entre o nome e o verbo, que deverão justificar a possibilidade de nominalização do infinitivo. Semanticamente, ambos podem ser núcleo de uma predicação e sintacticamente podem assumir distribuições parcialmente idênticas. Assim, como núcleo de um sintagma nominal, podemos ter um nome, mas também um verbo no infinitivo. Nesse caso, o infinitivo encontra-se nominalizado. A nominalização do infinitivo é uma construção cada vez mais recorrente, como comprova o corpus informatizado do CETEM Público ${ }^{41}$ :

(1) par=ext1206593-nd-94b-1: “(...)o desmoronar do império soviético (...)".

(2) par=ext1507248-pol-94a-2: “(...) o voltarem as costas à relação atlântica (...)".

Mas (1) e (2) ilustram duas construções diferentes de infinitivo: uma com propriedades nominais [(1)] e outra com propriedades verbais [(2)]. Na primeira construção, o verbo 'desmoronar' encontra-se nominalizado, precedido de artigo definido e seguido de genitivo, apresentando pro-

41 O corpus do CETEM Público é um corpus de imprensa escrita disponível on-line (http://acdc.linguateca.pt). Dada a extensão do trabalho, é apenas referido um exemplo de cada construção de nominalização do infinitivo. 
priedades nominais. Numa construção de infinitivo com propriedades nominais, o infinitivo pode aparecer com complemento genitivo, admite modificação adjectival, pode ser antecedente de uma relativa restritiva e pode ser coordenado com infinitivos do mesmo grupo. Na segunda construção, o verbo 'voltar' também se encontra nominalizado e seguido de acusativo, apresentando propriedades verbais. Numa construção de infinitivo com propriedades verbais, o infinitivo pode aparecer com acusativo, ter negação, pode ter auxiliares temporais, modais, aspectuais e admite modificação adverbial ${ }^{42}$.

Dada a frequência de ocorrências de nominalização do infinitivo no corpus do CETEM Publico, coloca-se a seguinte questão: será esta construção actual ou já existente em outros períodos do português? Se partirmos da hipótese de Mattos e Silva (2008: 25), segundo a qual o presente é a continuação do passado, então o mais natural é que esta construção já tenha existido em épocas anteriores da língua portuguesa. Considerando este pressuposto, analisarseá o uso nominal do infinitivo através dos corpora de épocas passadas.

Nesta perspectiva, é crucial analisar, num primeiro momento, o infinitivo em latim, procurando identificar quais os seus usos, diferenças e semelhanças com o infinitivo actual.

\subsection{Algumas considerações sobre o infinitivo latino}

O infinitivo latino apresentava diferentes tempos (presente, perfeito e futuro) e tinha voz activa e passiva. Dos três tempos, a forma mais frequente era a do infinitivo presente.

42 A construção de infinitivo com propriedades nominais é designada como 'infinitivo nominalizado' e a segunda construção, com propriedades verbais, é chamada 'nominalização de uma oração infinitiva'. Relativamente aos critérios que permitem distinguir estas duas construções, apenas os enumerei. Dado o âmbito deste trabalho, não ilustrarei cada um dos critérios. Para este assunto, consultar Plann (1981), Salvi (1983), De Miguel (1996), Picallo (1999), Hernanz (1999), Ramirez (2003) e Brito (2012). 
O infinitivo era considerado, juntamente com o gerúndio, o particípio passado e o supino, uma das formas nominais do verbo, designadas por uerbum infinitum. Além destas, possuía a conjugação latina o uerbum finitum, que englobava as formas do modo indicativo e as do conjuntivo. Assim, o infinitivo latino tanto apresentava traços verbais, com diferentes tempos e vozes, como apresentava traços nominais. Os traços nominais do infinitivo seriam as suas formas primitivas. Este aspecto é referenciado por diferentes autores: Ernout e Thomas (1953: 255), Palmer (1988: 317), Lisardo Rubio (1989: 249), Mariano de Climent (1983: 23) e Gildersleeve e Gonzalez Lodge (1986: 274).

Sendo o latim uma língua com declinações, o infinitivo usado enquanto substantivo possuía apenas dois casos, o nominativo e o acusativo. Os restantes (vocativo, genitivo, dativo e ablativo) eram dados pelo gerúndio e pelo supino. Isto é um caso de supletivismo, recorrendo-se a formas pertencentes a outros paradigmas (formas supletivas) para completar um paradigma defectivo. Este uso nominal do infinitivo aparecia sobretudo com as formas do infinitivo presente.

O uso nominal do infinitivo ocorria quando era predicativo do sujeito de esse, complemento de impessoais (decet, necesse est, oportet), verbos de vontade, poder e esforço (uolo, nolo, malo, cupio). Consoante a sua função sintáctica, o complemento tanto podia assumir o caso nominativo como o acusativo. Aparecia no nominativo quando o infinitivo dependia de verbos como uolo, cupio, possum, studeo e assim concordava com o sujeito. Aparecia no acusativo quando estava dependente de uma locução de sentido impessoal ou quando o predicativo do sujeito concordava com um sujeito indefinido implícito.

Os seguintes exemplos ${ }^{43}$ procuram ilustrar este traço nominal do infinitivo, assumindo as funções de um nome:

- sujeito: "non cadit invidere insapientem" (Cícero) - 'Não convém invejar o insensato'.

43 Os exemplos foram retirados da obra de Climent (1983: 360). 
- complemento directo: "bic vereri perdidit" (Plauto) - "este perdeu o respeitar - o sentido de respeito'; / "ego[ amo] esse et bibere"(Plauto) - 'eu cá por mim gosto é do comer e do beber'.

- predicativo do sujeito: "loquor de docto homine cui vivere est cogitare" (Cícero) - 'Falo acerca do homem douto para quem viver é reflectir'. - aposto: "illud est dulce, esse et bibere" (Plauto) - 'O que é agradável é comer e beber'.

Devemos notar que o infinitivo latino era do género neutro, como se poderá verificar no exemplo anterior, em que vem acompanhado de um nome predicativo do sujeito neutro.

O infinitivo etimologicamente era um nome, o que poderá explicar o seu uso nominal quer no latim ${ }^{44}$ quer na actualidade. Este uso nominal era mais visível no grego, dada a existência de artigos - que faltam em latim -, acreditando-se que terá sido por influência daquele idioma que, por via erudita, ocorreu o uso nominal do infinitivo em latim. Este uso nominal do infinitivo aparecia sobretudo para a expressão de ideias abstractas $^{45}$. Ao longo da evolução do latim, foi-se alargando o uso nominal do infinitivo, atribuindo-se-lhe marcas de nome, como o acompanhamento de adjectivo ou de genitivo ${ }^{46}$, acabando até por vir a ser regido por preposições. O uso nominal do infinitivo com preposição 'inter' é atestado em Cícero. Só numa época tardia surgiu o seu uso com outras preposições: 'contra', 'de', 'iuxta', 'ad'.

Concluindo, o uso nominal do infinitivo era o primitivo em latim e manteve-se em todos os períodos, coexistindo com o seu uso como verbo.

44 "Cependant, la fonction nominale de l'infinitif ne disparut pas; et une flexion rappelant celle de l'infinitif grec avec l'article lui fut constituée de caractère tout à fait hétéroclite d'ailleurs, puisqu'elle fait appel à deux formations fléchies, le supin et le gérondif" (Ernout e Thomas 1953: 254).

45 Este aspecto vem reforçar a caracterização de Bréal relativamente ao infinitivo: "El infinitivo es una conquista de la abstracción” (Bréal, apud Rubio, 1989: 249).

46 Os seguintes exemplos demonstram esta expansão do uso nominal do infinitivo: adjectivos determinativos meum amare (Plauto) (este meu amar); adjectivos qualificativos nostrum istud vivere triste (Plínio) (Este nosso triste viver); genitivo: quid autem huius vivere (Tert.) (Que espécie de viver é este). Os exemplos foram retirados da obra de Climent (1983: 360). 
Depois de caracterizado o infinitivo no latim, a sua formação e usos, procede-se à descrição das semelhanças e diferenças encontradas na forma do infinitivo actual.

\subsection{0 infinitivo no português}

No português actual, conservaram-se apenas as formas do infinitivo presente. As quatro conjugações do latim reduziram-se a três, desapareceu a terceira, sendo incluída ou na segunda ou na quarta conjugações. O infinitivo preserva uma forma composta, constituída pelo auxiliar 'ter' seguido do verbo principal no particípio passado. Por fim, importa salientar que, além do infinitivo impessoal, o português dispõe de um infinito flexionado.

À semelhança do latim, o infinitivo português também assume funções de sujeito, de complemento directo ou de predicativo. Cuesta e Da Luz (1980: 530), ao definirem os diferentes usos do infinitivo impessoal, realçam a sua função de substantivo verbal. Neves (2000: 70), no capítulo intitulado 'substantivo', também se refere ao infinitivo como forma nominal.

Como vimos anteriormente, o infinitivo latino era "un ancien substantif" (Ernout e Thomas, 1953: 255), tendo sido recuperado pelo latim e transformado numa forma verbal. No entanto, a sua função nominal não foi esquecida: a ocorrência de infinitivo nominalizado nos corpora actuais comprova esta situação.

Também Blake (1994: 183) e Haspelmath (1989: 291) referem a origem do infinitivo como substantivo ${ }^{47}$, resultando dos substantivos verbais no caso dativo, acusativo ou locativo.

47 "Indo -European linguistics have been aware for a long time that the infinitives of the ancient Indo - European languages (especially Latin, Ancient Greek, Old Indo-Iranian, Slavia, Hittite) go back to verbal nouns in the dative, accusative or locative case" (Haspelmath, 1989: 291). 
A noção de gramaticalização ${ }^{48}$ do infinitivo defendida por Haspelmath (1989: 291) parece ser pertinente no estudo do infinitivo nominalizado. $\mathrm{O}$ autor considera que, nas línguas indo-europeias, o infinitivo teve um percurso de evolução com várias etapas: de traços nominais fortes (sânscrito védico), a traços verbais (como o grego e o latim), terminando na morfologia de tempo e aspecto. Vários autores se debruçaram sobre o estudo do processo de gramaticalização, atribuindo-lhe diferentes fases. Hopper apresenta cinco etapas: estratificação, divergência, especialização, persistência e descategorização ${ }^{49}$. Transpondo as fases definidas por Hopper para o caso do infinitivo, pode concluir-se que, em latim, tendo ele sido inicialmente uma forma nominal, passou a ser também verbal, persistindo ambas as formas, isto é, juntando às primitivas propriedades nominais as verbais. Actualmente, no português, as duas formas existem, mas funcionalmente divergem, ou seja, houve uma especialização, sendo que o infinitivo com propriedades nominais só pode ocorrer em certos contextos e o infinitivo com propriedades verbais só noutros pode ocorrer. E dado que nas duas construções há traços da forma original, neste percurso existe ainda a etapa da persistência.

Em síntese, entre o infinitivo latino e o português há algumas diferenças, nomeadamente na redução dos seus tempos e conjugações e na existência de um infinitivo flexionado. No entanto, há também semelhanças no uso do infinitivo, aparecendo ora como forma verbal ora como nominal.

48 A noção de gramaticalização, sob uma perspectiva diacrónica, remonta a Meillet (1912). O autor considera que há três classes de palavras, nomeadamente, as principais, as acessórias e as gramaticais, havendo entre elas uma transição gradual. Neste sentido, as palavras gramaticais seriam fruto de um processo originado nas principais.

$49 \mathrm{Na}$ estratificação verifica-se a coexistência entre a forma velha e a nova; trata-se de um período de transição, pois a forma antiga não é imediatamente afastada. Devido à divergência, embora as duas formas coexistam, diferenciam-se funcionalmente. Deste modo, ocorrem casos onde um mesmo item lexical num contexto se torna gramaticalizado e noutro não. A especialização diz respeito a uma limitação das opções, tornando-se, em alguns contextos, obrigatória uma das formas. A persistência consiste no facto de alguns traços do significado lexical original de um item tenderem a aderir à nova forma gramatical, reflectindo-se, por vezes, na gramatical. Por descategorização entende-se a neutralização das marcas morfológicas e das propriedades sintácticas da categoria, pois dá-se uma perda de categoria. 
Num próximo momento, delimitar-se-á o corpus em estudo e analisar-se-ão as ocorrências de nominalização do infinitivo em duas sincronias do português.

\section{O corpus}

\subsection{Delimitação do corpus e sistematização dos resultados}

Conclui-se do exposto anteriormente que a nominalização do infinitivo era já um recurso que existia no latim. Neste momento, atentemos no caso do português medieval e do português clássico.

Assim, para o período medieval seleccionámos a primeira parte da Primeyra Partida. Para o período clássico, analisámos o Índice de Formas, de Paiva (2002), que contempla um corpus bastante extenso, abarcando o período de 1536 a $16066^{\circ}$.

Para um estudo mais objectivo, na análise da Primeyra Partida foram apenas contabilizadas as nominalizações do infinitivo que tinham marcas explícitas de nome: determinante ou adjectivo anteposto, pluralização, adjectivo à direita ou modificação por relativa. Numa coordenação de infinitivos, o segundo membro só foi contabilizado quando precedido de marca nominal. Esta opção poderá, em alguns casos, excluir da contagem certos infinitivos que, talvez por se encontrarem lexicalizados, aparecem sem determinação.

No que diz respeito ao corpus da Primeyra Partida, estão presentes sessenta e sete ocorrências de nominalizações do infinitivo, correspondendo a onze formas verbais. Dessas sessenta e sete ocorrências, trinta e uma aparecem antecedidas de artigo definido, oito de demonstrativo,

50 O corpus de Paiva (2002) abrange os seguintes autores e respectivas obras: Fernão d' Oliveira: Grammatica da lingoagem portuguesa, 1536; João de Barros: Texto contínuo da Cartinha,1539; Grammatica da língua portuguesa, 1540; Diálogo em louvor da nossa linguagem, 1540; Pêro Magalhães de Gândavo: Regras que ensinam a maneira de escrever e Orthographia da língua Portuguesa,1574; Dialogo em defensã̃ da língua Portuguesa, 1574; Duarte Nunes de Leão: Ortographia da Lingoa Portuguesa, 1576; Origem da Lingoa Portuguesa, 1606. 
duas de um quantificador, vinte e duas de possessivo, quatro modificadas por adjectivo e quatro por uma relativa. Por fim, de nominalizações do infinitivo com plural existem dez ocorrências, correspondendo às seguintes formas verbais: 'poderes', 'saberes', 'comeres' e 'aueres'. Somente ocorre o plural nestes infinitivos lexicalizados. Das formas verbais infinitivas substantivadas, a maioria inscreve-se na classe dos verbos de estado.

Paiva (2002: 112) considera que a nominalização do infinitivo é um processo bastante frequente: "A transferência de classe do adjectivo, do particípio passado e do infinitivo impessoal para a classe do substantivo, mediante anteposição do artigo definido, constitui um recurso permanente de expressão, por aplicação de uma regra de sintaxe”.

No Índice de Formas, de Paiva (2002), pesquisámos todas as formas verbais infinitivas usadas como substantivo. Quando ocorrem casos de transferência de classe gramatical, Paiva (2002) indica em primeiro lugar a classe funcional em que determinada ocorrência será contabilizada e seguidamente indica a classe originária, separando as duas por um sinal de proveniência, ou seja, inicialmente é indicada a função que o vocábulo desempenha na frase e depois a sua origem. Neste caso, seleccionámos todas as formas verbais que tinham a seguinte classificação: $s t<v b a$ que significa que a classe funcional é a de substantivo (st) e a classe originária é a de verbo $(v b)$ no infinitivo impessoal $(a)$.

Nesta classificação, a autora distingue as transferências lexicalizadas e as transferências não lexicalizadas. A substantivação não lexicalizada do infinitivo é dada a partir do processo anterior: $s t<v b a$. Quando a transferência surge lexicalizada, sendo a marca do plural um dos traços caracterizadores, classifica a forma apenas como substantivo: st. No entanto, não sendo a pluralização o traço essencial para considerar a lexicalização de um determinado vocábulo, a autora procura também verificar "a gradação entre o traço inovador do discurso e a generalização desse traço, com consequente consolidação do conteúdo concreto" (Paiva, 2002: 113).

No Índice de Formas, de Paiva (2002), aparecem vinte e seis formas verbais infinitivas usadas como substantivo que correspondem a noventa e duas ocorrências. Destacam-se apenas duas formas pluralizadas: 'entenderes' e 'pareceres'. 
Como formas verbais classificadas apenas como substantivo, ou seja, em que não há transferência de categoria, estando já devidamente lexicalizadas, temos dezasseis ocorrências, correspondendo às seguintes formas verbais: 'entender', 'falar, 'auer', 'parecer', 'poder', 'saber' e 'ser'.

\subsection{Discussão dos resultados}

No período medieval e clássico, a ocorrência de infinitivos nominalizados demonstra que este processo já existia.

Se analisarmos a razão entre o número total de ocorrências de infinitivo nominalizado e o número de formas infinitivas usadas, verificamos que é mais baixa no período clássico do que no medieval. Assim, neste, a razão é de 6,09 (67/11) e naquele a razão é de 3,54 (92/26). Quanto mais baixa a razão, mais produtivo é o processo de nominalização. Podemos concluir que há expansão da nominalização do infinitivo a um maior número de infinitivos. Enquanto no texto medieval encontramos onze formas infinitivas diferentes, no corpus clássico ultrapassa o dobro (vinte e seis formas verbais diferentes).

No entanto, se analisarmos o período clássico, os vários autores presentes no corpus e a frequência de nominalizações do infinitivo que aparece em cada um, verifica-se um maior número de ocorrências em Fernão de Oliveira e João de Barros, ou seja, na primeira metade do século XVI, do que em Gândavo e Leão, isto é, na segunda metade do século XVI. Paiva (2002) refere que no seu corpus existia um período de transição, um vazio editorial de trinta e quatro anos. Analisando os diferentes autores, verificamos um maior número de nominalizações do infinitivo na primeira metade do século XVI.

A aparente diferença entre a primeira metade do século XVI e a segunda metade do século XVI justifica-se pelo facto de nesta segunda sincronia o corpus de Paiva (2002) estar limitado a apenas um quarto de cada obra dos diferentes autores. Sendo assim, poder-se-á concluir que na segunda metade do século XVI, a frequência de nominalizações do infinitivo seria semelhante à da primeira metade 
desse século, indiciando uma continuidade e uma manutenção dos mesmos dados.

A produtividade deste processo de nominalização do infinitivo encontra-se sobretudo no século XVI, embora já desde o mais antigo período da língua portuguesa existam exemplos deste processo. Em fase posterior do meu trabalho, pretendo analisar documentação do século XV.

\subsubsection{Os infinitivos lexicalizados 51}

No corpus apresentado e analisado, verificou-se a ocorrência de infinitivos nominalizados no plural, o que significa que estas formas já estariam lexicalizadas como nomes.

A lexicalização é um processo a partir do qual uma forma linguística se torna mais lexical. A lexicalização é vista como uma mudança histórica da qual resulta a produção de uma nova forma lexical. O input deste processo inclui palavras compostas, construções sintáticas e itens gramaticais e o seu output é lexical. Este processo é gradual, de uma escala de menos lexical para mais lexical, podendo ocorrer mudanças morfológicas, fonológicas e semânticas.

De acordo com Brinton e Traugott (2005: 20), diacronicamente este conceito é usado para referir "adoption into the lexicon" ou "falling outside the productive rules of grammar" 52 . Assim, ocorre lexicalização quando um item se torna convencionalizado, começando a pertencer ao inventário lexical de uma dada língua ("adoption into the lexicon"). Os autores interligam o conceito de lexicalização com o de institucio-

51 Os infinitivos lexicalizados apresentam diferentes nomenclaturas de acordo com os vários autores. Varela, (1979) define estes infinitivos como "falsos infinitivos"; Lapesa (1985) apud Cacoullos, como "puros sustantivos totalmente deverbalizados" e Gili Gaya (1943) como "sustantivos permanentes".

52 Combinando estas duas perspetivas, os autores definem lexicalização como: "lexicalization is the change whereby in certain linguistic contexts speakers use a syntactic construction or word formation as a new contentful form with formal and semantic properties that are not completely derivable or predictable from the constituents of the construction or the word formation pattern. Over time there may be further loss of internal constituency and the item may become more lexical" (Brinton e Traugott, 2005: 96). 
nalização, ou seja, fixação de uma forma linguística numa determinada comunidade. No segundo caso ("falling outside the productive rules of grammar”), a lexicalização ocorre quando uma forma já não pode ser descrita de acordo com as regras regulares da gramática. A lexicalização apresenta um conjunto de processos, interligando-se, a nível diacrónico, com os processos de fusão (sequências complexas tornam-se simples, havendo uma diminuição da autonomia) e separação (aumento de autonomia).

Brinton e Traugott (2005: 21) caracterizam ainda a lexicalização como um processo resultante de mudanças inferidas pelo significado convencionalizado, nomeadamente a partir da polissemia semântica e pragmática. Estas interpretações semânticas ou pragmáticas seriam determinadas pelo contexto, sobretudo os bridging contexts, nomeadamente contextos específicos que permitem a inferência de um novo significado. Efectivamente o contexto é um conceito chave não só para a lexicalização, mas também na gramaticalização.

Heine (2002) analisa precisamente o papel do contexto não na lexicalização, mas na gramaticalização. Defende, dessa forma, que na gramaticalização, a evolução das categorias gramaticais é dependente do contexto, podendo ser descrita por meio de diferentes estádios interligados com os tipos de contexto. Em cada estádio interliga o contexto com a conceptualização e caracteriza, assim, quatro estádios: estádio inicial, contextos bridging, contextos switch e convencionalização. No primeiro estádio, o item aparece no contexto em que é usado normalmente; no segundo, um dos contextos em que o item é usado permite uma inferência e um novo significado (contexto bridging); no terceiro, num contexto de switch, somente o novo significado é permitido, mas ainda está interligado com aspectos contextuais e no último estádio já não são necessárias restrições contextuais, permanecendo o novo significado. $\mathrm{O}$ terceiro estádio é importante para a mudança, podendo dar origem ao significado convencional. Este estádio é caracterizado por ambiguidade estrutural e semântica, convidando a diferentes interpretações.

Nos corpora analisados anteriormente, encontrámos infinitivos lexicalizados. Assim, na Primeyra Partida apareciam dez ocorrências de 
infinitivos nominalizados pluralizados, correspondendo às formas verbais - 'poderes', 'saberes', 'comeres' e 'aueres'. No Índice de Formas, existiam dezasseis ocorrências de infinitivos nominalizados já lexicalizados, correspondendo às formas verbais: 'entenderes', 'pareceres', 'entender', 'falar', 'auer', 'parecer', 'poder', 'saber' e 'ser'. No português actual, todas estas formas se encontram lexicalizadas, possuindo nos dicionários uma entrada própria, o que significa que a lexicalização está prevista na língua. Assim, de acordo com o conceito de Brinton e Traugott (2005), estas formas já estão convencionalizadas.

Efectivamente, a entrada das nominalizações lexicalizadas no dicionário é fruto de uma evolução histórica e da sua frequência ao longo desse proceso. Como afirma Pena (1976: 26) a lexicalização é um: "proceso histórico que resulta en la associación de una nominalización con un significado, muchas veces no transparente semanticamente, esto es, no recuperable del verbo del que deriva".

Lapesa (1984:68-73) considera quatro classes nos infinitivos lexicalizados em espanhol: os infinitivos consolidados como substantivos (lexicalizados) que admitem plural, dando como exemplos: aver/haber, cantar, comer, yantar, pesar, placer, querer, andar, saber, decir, parecer, ser, proceder, sentir, amanecer, deber, anochecer, atardecer, acontecer; os infinitivos consolidados como substantivos, com aceção distinta da ação verbal e sem plural atestado como cuydar, catar, beber, entender, valer, ver; os infinitivos sujeitos a substantivação ocasional sem plural conhecido como versificar, calçar, vestir e os infinitivos sujeitos a substantivação ocasional com plural omo velares, traeres, taneres, dares e tomares.

Nesta classificação de Lapesa (1984:68-73) incluímos 'aueres', 'comeres', 'pareceres', 'saberes' no primeiro grupo. Contrariamente à classificação do autor, incluiremos também 'entenderes' neste primeiro grupo, dado que aparece com plural.

Consideramos que o facto de os infinitivos lexicalizados já aparecerem em textos mais antigos com a forma de plural contribui para a sua manutenção na língua e justifica a sua grande ocorrência actualmente. Os infinitivos lexicalizados encontrados nesses textos são precisamente os que hoje em dia encontramos mais frequentemente nos corpora. 


\section{Conclusão}

O estudo do infinitivo latino revelou-se importante para compreender o uso nominal do infinitivo português. Verificou-se que o infinitivo, etimologicamente, era uma forma nominal que depois foi introduzida no latim como forma verbal. Justificou-se deste modo a ocorrência actual de uma forma que, à partida, seria um verbo e que está a ser aplicada como forma nominal. O seu uso nominal não desapareceu, havendo ocorrências dele no latim. Apesar de serem poucas as ocorrências, estas foram-se desenvolvendo, ao longo dos vários períodos do português.

Na passagem do latim para o português, houve algumas alterações; nomeadamente, dos três tempos do infinitivo latino, permaneceu apenas um, o presente. Não esqueçamos que era sobretudo esse tempo que no latim ocorria nominalizado, facto que mais uma vez explica as suas ocorrências nominais actuais.

$\mathrm{Na}$ análise do infinitivo, há autores que defendem que este foi sofrendo um processo de gramaticalização, que ainda está em curso. Efectivamente, defendemos que tal hipótese é viável. Partindo das várias fases definidas por Hopper, enquadrámos a sua evolução respectivamente na estratificação, na divergência, na especialização e na persistência, ou seja, a coexistência atual dos valores verbais e nominais.

$\mathrm{Na}$ análise dos corpora dos períodos medieval e clássico, respondemos ao nosso primeiro objectivo delineado na introdução e concluímos que este processo de nominalização do infinitivo já ocorria em textos do passado dos séculos XIII, XVI e XVII. Verificou-se que o período de maior produtividade se situava no século XVI. As formas nominalizadas do período clássico eram superiores às do período medieval.

Relativamente ao segundo objectivo, observámos nos corpora exemplos de infinitivos lexicalizados que apareciam, inclusive, pluralizados. Consideramos que é precisamente a sua existência e frequência em textos do passado a justificação desta mesma ocorrência no português actual. $\mathrm{O}$ aparecimento destes infinitivos lexicalizados em textos do passado demonstra que este novo lexema começou a ser institucionalizado, a ser aceite pela comunidade linguística, tornando-se num item lexical. 
Efectivamente, como diz Coseriu (1979: 237), A lingua ...é um fazer-se num quadro de permanência e continuidade.

\section{Referências bibliográficas}

Ali, M. Said (1964): Gramática Histórica da Língua Portuguesa. São Paulo: Edições Melhoramentos.

Blake, Barry J. (1994): Case. Cambridge: Cambridge University Press.

Brinton, Laurel J. / Traugott, E. C. (2005): Lexicalization and language Change. Cambridge: Cambridge University Press.

Brito, Ana Maria (2012): O infinitivo nominal em Português Europeu: aspectos sintácticos e semânticos. In: Costa, Armanda / Duarte, Inês (edd.): Nada na linguagem lhe é estranho. Estudos em homenagem a Isabel Hub Faria. Porto: Edições Afrontamento, 109-126.

Cacoullos, Rena Torres. Las nominalizaciones de infinitivo. [On-line], disponível em: <http:// www.personal.psu.edu/rct11/Resources/Publications/Nominalizacion\%20Infinitivo. Sintaxis\%20Hist\%C3\%B3rica.pdf>. [Consultado em: 10 set. 2010].

Cardeira, Esperança (2005): Entre o português Antigo e o português Clássico. Tese de doutoramento. Lisboa: Imprensa Nacional.

Cardeira, Esperança (2009): Revisitando a periodização do português: o português médio. [Online], disponível em: <http://www.dominiosdelinguagem.org.br/pdf/dl6/DL\%206\%20-\%207. pdf $>$. [Consultado em: 10 set. 2010].

Camara Junior, Joaquim Mattoso (1975): História e Estrutura da Língua Portuguesa. Rio de Janeiro: Padrão.

Climent, Mariano Bassols de (1983): Sintaxis Latina. Madrid: Consejo Superior de Investigaciones Cientificas.

Coseriu, Eugenio (1979): Sincronía, diacronía e bistória. Rio de Janeiro: Presença.

Cuesta, Pilar Vasquez / Da Luz, Albertina Mendes (1980): Gramática da Língua Portuguesa, trad. port. Lisboa: Ed. 70, 404-451.

Cunha, Celso /Cintra, Lindley (2002): Nova Gramática do Português Contemporâneo. Lisboa: Edições João Sá da Costa.

De Miguel, Elena (1996): Nominal Infinitives in Spanish: an Aspectual Constraint. In: Canadian Journal of Linguistics, 41:1, 29-53.

Ernout, Alfred / Thomas, François (1953): Syntaxe Latine. Paris: Éditions Klincksieck, 7-14, 215-229, 255-272.

Gili Gaya, Samuel (1943): Curso Superior de Sintaxis espanola. México: Ediciones Minerva.

Gildersleeve, B.L. / Lodge, Gonzalez (1968): Latin Grammar. New York: ST Martin's Press.

Haspelmath, Martin (1989): From Purposive to infinitive. A universal path of grammaticalization. [On-line], disponível em: http://email.eva.mpg.de/ haspelmt/1989inf.pdf [Consultado em: 25 dez. 2010].

Heine, Bernd (2002): On the role of context in grammaticalization. In: Wischer, Ilse / Diewald, Gabriele (edd.): New Reflexions on Grammaticalization. Amsterdam/Philadelphia: John Benjamins Publishing Company, 83-101.

Herman, József (2000): El latín vulgar. Madrid: Ariel. 
Hernanz, Maria Lluïsa (1999): Los usos nominales del infinitivo. In: Bosque, Ignacio / Demonte, Violeta (edd.): Gramática Descriptiva de la Lengua Española. Espasa: Madrid, vol II, 2342-2356.

Lapesa, Rafael (1984): El uso de actualizadores con el infinitivo y la suboración sustantiva en español: diacronía y sentido. In: Lapesa, Rafael (2000): Estudios de morfosintaxis bistórica del español. Madrid: Gredos, 515-556.

Mattos e Silva, R. V. (2008): O Português arcaico: uma aproximação. Lisboa: Imprensa Nacional-Casa da Moeda, Vol.I, 302-349; Vol.II, 74-88.

Paiva, Maria Helena Pinto Novais (2002): Os gramáticos portugueses quinhentistas e a fixação do padrão linguístico. Contribuição da informática para o estudo das relações entre funcionamento, variação e mudança. Tese de Doutoramento. Porto: Faculdade de Letras.

Palmier, L.R. (1988): The Latin Language. London: Faber Limited.

Pena, Jesús (1976): Usos anómalos de los sustantivos verbales en el español actual. In: Verba, Anuario Gallego de Filología, Anejo 6. Santiago de Compostela: Universidad de Santiago de Compostela.

Picallo, Carme (1999): La estructura del sintagma nominal: las nominalizaciones y otros sustantivos con complementos argumentales. In: Bosque, Ignacio / Demonte, Violeta (edd.): Gramática descriptiva de la lengua española. Tomo 1 Sintaxis básica de las clases de palabras. Madrid: Espasa/Calpe, 363-393.

Plann, Susan (1981): The two el+infinitive constructions in Spanish. In: Linguistic Analysis, 7, 3, 207-241.

Ramírez, Carlos Julio (2003): The Spanish Nominalized Infinitives: a proposal for a classification. [On-line], disponível em:

<http://twpl.library.utoronto.ca/index.php/twpl/article/view/6226/3215>.[Consultado em: 17 abr. 2011].

Rubio, Lisardo (1989): Introducción a la sintaxis estructural del latín. Barcelona: Ariel.

Salvi, Gianpaolo (1983): L'infinitivo con l'articolo e la strutura del SN. In: Rivista di Grammatica Generativa, vol 7, 197-225.

Varela Ortega, Soledad (1979): Los falsos infinitivos. In: Boletín de La Real Academia Española, 59: 218, 529-551.

Vilela, Mário (1994): Estudos de lexicologia do português. Coimbra: Almedina.

Vilela, Mário (1995): Léxico e gramática. Coimbra: Almedina. 